Research Paper:

\title{
Effects of an Educational Intervention on Self-Care and Metabolic Control in Patients With Type II Diabetes
}

\author{
Mahnoush Reisi ${ }^{1}$, Homamodin Javadzade ${ }^{1}$, Gholamreza Sharifirad ${ }^{2}$, Firoozeh Mostafavi ${ }^{3}$, Elahe Tavassoli ${ }^{4}$, Masoumeh Imanzad ${ }^{5 *}$ \\ 1. Department of Health Education and Health Promotion, School of Health, Bushehr University of Medical Sciences, Bushehr, Iran \\ 2. Department of Public Health, School of Health, Qom University of Medical Sciences and Health Services, Qom, Iran. \\ 3. Department of Health Education and Health Services, School of Health, Isfahan University of Medical Sciences, Isfahan, Iran \\ 4. Department of Public Health, School of Health, Shahrekord University of Medical Sciences, Shahrekord, Iran. \\ 5. Department of Social Medicine, School of Medicine, Shahid Beheshti University of Medical Sciences, Tehran, Iran.
}

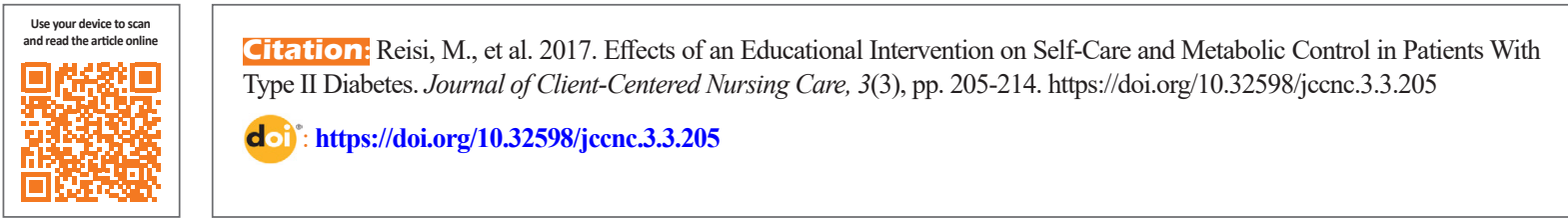

Article info:

Received: 02 Feb. 2017

Accepted: 13 Jun. 2017

Keywords:

Self-efficacy, Outcomeexpectations, Self-care behaviors, Metabolic control, Intervention, Type-2 diabetes

\begin{abstract}
A B S T RA C T
Background: Although compliance with all self-care behaviors is necessary for successful management of diabetes, patients with diabetes often refuse favorable self-care. This article is aimed to test the effects of a theory-related intervention to conduce self-aid adherence and metabolic curb in patients having type- 2 diabetes.

Methods: In this randomized controlled trial, 80 patients suffering from type- 2 diabetes were arbitrarily allotted to intervention and control group. The intervention group attended six sessions in a batch and one-on-one consultation and received an education on self-efficacy and outcome expectations on improving the strategies. Self-efficacy, outcome expectations, self-care behaviors and $\mathrm{HbAlc}$ were measured and compared in two groups in the starting, after three and six-months of the interventions. "Intention to treat" analysis was used. Data were analyzed using $t$ test and ANOVA for repeated measures.

Results: Mean score of self-efficacy, outcome expectations and self-care behaviors revealed significant differences between two groups in the results of three and six months after the intervention $(\mathrm{P}<0.01)$. A major fall in $\mathrm{HbAlc}$ was noted in the intervention group. The mean scores of the $\mathrm{HbAlc}$ showed a significant difference between two groups, six months after the intervention $(\mathrm{P}<0.05)$. After the intervention diet, physical activity and foot care improved significantly in the intervention group $(\mathrm{P}<0.001)$. No significant improvement occurred in self-monitoring of blood glucose and medication adherence between two groups after the intervention
\end{abstract}

Conclusion: It is concluded that implementing educational interventions based on the self-efficacy model and related strategies can be effective for patients with type-2 diabetes and is recommended to be used for patient education in the field of metabolic control.

\footnotetext{
* Corresponding Author:
}

Masoumeh Imanzad, MSc.

Address: Department of Social Medicine, School of Medicine, Shahid Beheshti University of Medical Sciences, Tehran, Iran

Tel: +98 (21) 46031801

E-mail:imanzad96@gmail.com 


\section{Background}

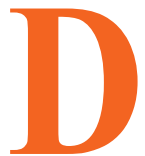

iabetes is not only a chronic ailment but also a worldwide health concern. The prevalence of diabetes has been rapidly increasing and has become a major worldwide health problem of this century (Zhou et al. 2013, Reisi et al. 2016). The International Diabetes Federation (IDF) reports are indicative of 382 million diabetic patients existing worldwide in 2013. According to the prediction of this organization, the number of such people in 2035 will be about 592 million, more than $80 \%$ of which live in low and middleincome countries (Wild et al. 2004, Yang et al. 2010). According to the IDF statistics, in 2010, about $6.1 \%$ of the 20 to 79-year-old population of Iran had diabetes. According to the estimations of this organization, up to 2030, Iran will be one of the highly prevalent areas of diabetes in the world and the prevalence will rise from 6.1 to $9.3 \%$, i.e. approximately 6 million people (Sicree, Shaw \& Zimmet 2010).

There is a rising consideration to diabetes and its sufferers because of the chronic complications and problems that emerge over time in such patients leading to high disability and mortality rate (Morrish et al. 2001; Roglic et al. 2005). In 2014 alone, diabetes has caused 4.9 million deaths in the world according to IDF (International Diabetes Federation).

Although there is no definite cure for diabetes, proper care can be effective in control of symptoms and prevention of its debilitating effects; it requires control of blood glucose and keeping it in the optimal range (Brettenthaler et al. 2004, Didarloo et al. 2012). Some studies have shown that for every $1 \%$ reduction in $\mathrm{HbA} 1 \mathrm{C}$, the risk of developing eye, kidney and nerve complications will be reduced by more than $40 \%$ (Nath, 2007) and $7 \%$ of treatment costs will be saved (Sigurðardóttir, 2005) in the diabetic patients.

The fundamental solution to control blood glucose and effective management of diabetes is patient's accountability to perform self-care behaviors (Wu, 2007). A study showed that self-care behavior predicts $66 \%$ of changes in glycosylated hemoglobin, an important indicator of blood sugar control in type-2 diabetes sufferers (Sorani et al. 2012). Self-care behavior in people with diabetes includes self-observation of blood sugar levels, adherence to appropriate nutrition, medication adherence, physical exercise, and foot care (Tan \& Magarey 2008, Franz et al. 2004).
Although compliance with all self-care behaviors is necessary for successful management of diabetes, an international study suggests that patients with diabetes often refuse favorable self-care and only $16.2 \%$ of them follow the advice provided by health professionals and have a desirable level of self-care (Funnell 2006).

In this regard, WHO has considered patient education as an important strategy to improve the active participation of patients in the management of their disease (Eckman et al. 2012), and has focused on the use of educational strategies in order to empower patients to participate in the process of treatment, management, and control of diabetes (Wu 2007).

Since a person's behavior is a reflection of various factors, by recognizing the behavior and the most important factor affecting it, theory-based interventions with the best educational strategies can be designed to change and improve behaviors (Bashirian et al. 2012, Miller \& Gutschall 2008). Although various individuals and environmental factors affect self-care behaviors in patients with diabetes, review of results show that self-efficiency is considered as the most powerful predictive factor to adjust self-care behavior in patients with diabetes (Reisi et al. 2015; King et al. 2010; Aljasem et al. 2001). On the other hand, since considering attitudinal construct of outcome expectations with self-efficacy in educational interventions doubles the effectiveness of interventions (Bandura 1986), self-efficacy model provided by Shortridge-Baggett and Van der Bijl (1996) was utilized in this study as a conceptual structure. Self-efficacy model is derived from two theories of self-efficacy and outcome expectations that are the main concepts in the social cognitive theory presented by Bandura. This model is based on the fundamental premise that people's expectations of their efficacy to perform the behavior (self-efficacy), as well as their expectations of achievements and successes obtained as a result of the behavior (outcome expectations), are the two main psychological determinants for engaging in and complying with a certain behavior (Wu 2007). Eventually, the objective of this study was to test the efficacy of a theory-based intervention to encourage self-care adherence and metabolic control in a group of diabetics.

\section{Materials and Methods}

The study protocol got its approval from the Ethics Committee of Research and Technology department of the Isfahan University of Medical Sciences (No. 393268). In this randomized controlled trial, 80 participants were recruited from an Imam Ali diabetes clinic 
in Isfahan, Iran from August 2015 to March 2016. This clinic provides outpatient care by physicians and nurses to diabetic patients. Total 34 patients were required in each group based on the confidence interval of 0.95 , test power of 0.8 , and assuming a standard deviation of the primary outcome, based on a previous study (Moattari et al. 2012). However, samples of 80 patients were assumed to be sufficient to compensate for $20 \%$ attrition rate. For sampling, after reviewing the records of patients in Imam Ali clinics $(\mathrm{N}=1639), 80$ patients were selected using the simple random method. After a phone call, people who would like to participate in the study were identified and then randomly divided (with flip of coin) in two groups of theory-based educational intervention and control group with flip the coin method. Figure 1 shows the consort flow of participants in the study.

Inclusion criteria included an age greater than 25 years, lack of severe complications of diabetes such as nephropathy, retinopathy and neuropathy, absence of any mental, visual, and learning disabilities, and willingness to participate in the study. Participants who did not attend classes for more than one session or faced with severe side effects caused by diabetes during the study were excluded. All participants signed their written informed consent. The patients could leave the study at any time and their information would be kept confidential and anonymous.

For data collection in the study, a demographic questionnaire consisting six questions regarding age, sex, marital status, education level, occupation and duration of disease was used. Diabetes Management Self-Efficacy Scale (DMSES) questionnaire was used to assess self-efficacy in patients. This instrument was prepared in 1999 by Bijl van der, Poelgeest-Eeltink and ShortridgeBaggett (1999) to measure confidence rate of diabetic patients to perform in self-care behaviors. This questionnaire includes 20 questions and the answers to these questions are scored at 11-degree Likert scale from "I cannot at all" (0) to "Certainly I can" (10). In Iran, the validity and reliability of this instrument were examined by Haghayegh et al. (2010). The instrument's coefficient of internal consistency has been reported as 0.83 and its retest coefficient $(r=0.86, P<0.001)$ is acceptable.

A 20-item Outcome Expectancies Questionnaire (OEQ) designed by Skelly et al. (1995) was used to assess the patients' expectations from outcomes of selfcare behaviors. The patient selects a response for each item from 0 (Totally disagree) to 100 (Totally agree). The total score equals the sum of all item scores. Higher scores reflect the stronger belief that diabetic behaviors will result in specific outcomes. The Cronbach's $\alpha$ coefficient for the study instrument was 0.80 .

The questionnaire was used to measure the Summary of Diabetes Self-Care Activities (SDSA) designed by Toobert et al. (2000). This instrument assesses self-care behaviors in diabetic patients during the last seven days. The adherence of patients to perform self-care behaviors was assessed by a total of 12 questions. The answer to each question is placed in a range from 0 to 7 , the minimum and maximum scores obtained by the patients are 0 and 84 , respectively. The questionnaire is also validated in other languages, and its validity and reliability have been proven in previous studies (Wu 2007).

Determining the percentage of glycosylated hemoglobin is considered as an important diagnostic tool for monitoring blood sugar level. This test is the most reliable evaluation method for the treatment of hyperglycemia in diabetic patients (Piccinino et al. 2015). This study is done in the laboratory through an enzymatic method that specifically measures the N-terminal fructosyl dipeptide of glycosylated hemoglobin beta chain.

In the intervention phase, patients in the intervention group have continuously participated in six educational sessions. At first, these patients were divided into smaller groups so that in each group, the number of participants ranged from 10 to 15 . The first five sessions were in groups, and the sixth session was in a face-to-face form. Face to face counseling was provided to set goals for each patient. Duration of each session was 50-60 minutes on an average. Also, two telephonic follow-ups were performed for two months after the intervention. Since the intervention was based on the self-efficacy model, a set of strategies were used to increase self-efficacy in patients and improve outcomes of their expectations during educational sessions and outside, to enhance self-care and improve blood glucose control.

\section{Self-efficacy improvement strategies}

In the present study, these important resources were used to improve self-efficacy in patients to perform better self-care behaviors (Figure 2):

\section{Performance accomplishments}

Performance accomplishments involve practicing and experiencing success in achieving goals. In this study, we used 4 steps of goal-setting approach; this included recognizing the need for change, establishing a goal, monitor goal-related activity, and rewards for goal at- 
tainments. By setting small goals with the partnership of the patients and helping them achieve the set goals, the patients were pushed towards the larger goals. In fact, after successful completion of specified activities, patients gained a stronger sense of efficacy; this not only created a pleasant feeling but also increased the likelihood of success repetition.

During sessions, step by step performance of selfcare behaviors and beginning from small activities was emphasized. After educating about every self-care behavior, in subsequent sessions the patients were asked to report their performance orally or in writing (recorded on the sheets containing the schedule to record the behavior of patients on weekdays). Reporting any successful experience provided reinforcing feedback by the educator. In the last session, which was held in a face-to-face interview, "Action plan form of change beginning" was completed and particular goals were determined by patients and under the guidance of educator. During the educational sessions and phone follow-ups, successful experiences of self-care behaviors were encouraged. Since successful experiences increase self-efficacy of people, continuous failures, especially if they happen in the early behavior run, can decrease self-efficacy. So, we tried to make a context in which the patients could achieve successes in the early stages, even if they are small.

\section{Vicarious experience (succession)}

Vicarious experiences allow one to judge behavior based on the performance of others. In fact, others can play the role model for the person and provide information on the considered behavior. When people perceive the model is more similar to themselves, the models will have more effects on their success and failure (Bandura 1986; Van der Bijl \& Shortridge-Baggett 2001).

In this study, role models were used as one of the strategies to increase self-efficacy in two forms. First, the successful patients participating in the research project (patients who followed the advice well) were identified by the educator, and were introduced as models in educational classes and questioned them about successes achieved, their performance, possible barriers and ways to overcome them, in order to adjust patients' beliefs about their efficacy to perform self-care. Second, four patients (Two men and two women) who had controlled their blood sugar according to their medical history in the healthcare center, were identified by the researcher; and they were invited to participate in the educational sessions. Since some of these patients previously had very poor blood sugar control and were able to improve their situation only with proper self-care and get favorable blood sugar levels, their presence in sessions could affect patients' beliefs about the feasibility of blood sugar control and having a normal and pleasing life. Also, because these people had provided proper information to patients and convinced them that the challenges on the way are surmountable, patients were encouraged well and the belief that "if others have been able to do the considered behavior, they can too," was strengthened in them. Then a free physician visit was given to the model patients as a reward.

\section{Verbal persuasion}

Verbal persuasion can target both self-efficacy and outcome expectation factors in people and eventually lead them to a change in their behavior (Sherer et al. 1982). Since this technique can be beneficial if it is used by individuals after the success of a certain behavior, we encouraged the patients after performing or reporting self-care behaviors in a correct way, and emphasized on their capabilities along with verbal feedback in possible opportunities. Although this technique alone may not be effective in improving self-efficacy in patients, according to Bandura, if it is used together with other sources of increasing efficacy, it could be effective in improving patients' expectations from efficacy (Wu 2007; ShortridgeBaggett and Van der Bijl 1996).

\section{Physiological/emotional states}

High levels of stress and anxiety (a physiological/ emotional states) are considered as negative feedbacks that can reduce patients' confidence and affect their performance (van der Bijl \& Shortridge-Baggett, 2001; Bandura 1997). Usually, people assume experiences like stress and anxiety as personal shortcomings. So in activities that require strength and perseverance, they take negative interpretations as indicators and signs of physical dysfunction (Wu 2007; Bandura 1997).

In the present study, some patients refused to comply with some recommendations regarding self-care behaviors such as proper diet and physical activity because of fear of hypoglycemia. In fact, they knew hypoglycemia as a sign of physical inefficiency, and this led to the failure in performing self-care properly. In this regard, the educator initially sets smaller goals to create the belief in patients that they can achieve their goals (adherence to proper diet and physical activity) without challenge. Also, patients were informed about the symptoms of hypoglycemia, accurate way to 
determine it, and its appropriate treatment so that they would not go wrong in recognizing hypoglycemia. It was also ensured that they could take appropriate measures even in case of such situation.

\section{Strategies to improve outcome expectations}

To improve patients' beliefs about the outcome of performing self-care behaviors, psychological and physical benefits of proper self-care were repeatedly emphasized. In this regard, comments, experiences, and positive experienced outcomes of patients were highlighted, and adherence to self-care behaviors in other patients was emphasized to achieve similar outcomes. On the other hand, negative outcomes expected or experienced by patients about self-care behaviors were presented and discussed with them to modify these beliefs and appropriate solutions to help patients do not experience negative outcomes, was presented.

Finally, participants in the intervention and control groups were evaluated three and six months after the intervention. In order to comply with ethics, necessary precautions were considered to respect patients' privacy and confidentiality of their information, especially during group educational interventions. Before the intervention, all patients completed and signed the research informed consent form after studying it and clearing possible ambiguities. The study also followed the principles delineated in the Declaration of Helsinki (World Medical Association 2001).

\section{Statistical analysis}

Statistical analysis of frequencies of each variable was performed to check the accuracy of data entry. Descriptive analysis was done for demographic variables, self-efficacy and self-care behaviors of type-2 diabetes, outcome expectations towards self-care behaviors and $\mathrm{HbA} 1 \mathrm{C}$. The mean (SD) for continuous variables and No. (\%) for the dichotomous or nominal data were calculated. Before evaluating the effects of the theory-based intervention, differences between the groups on a range of variables were examined. " $t$ " test was used to analyze differences between continuous data among mean scores for the intervention and control groups. Nominal data were analyzed using Chi-square statistics to test the significance of different proportions. To assess the group differences of dependent variable changes, we used ANOVA for repeated measures. $\mathrm{P}$ of less than .05 level was used for all statistical inferences.

\section{Results}

During the study, with the attrition made during the interventions ( 3 due to the absence in sessions more than once) and in the follow-ups ( 2 for the intervention-group and 4 for control group because of refusal to continue participating in research project, not taking $\mathrm{HbA1c}$ test in the set timeframe or personal problems) finally, the statistical analysis was performed in the intervention group and the control group for 35 (87.5\%) and $36(90 \%)$ patients, respectively. Before evaluating the effects of the intervention, differences between the groups on a range of variables were examined, and no significant differences were found between the intervention and the control groups on socio-demographic characteristics (Table 1).

The results of the $t$ test indicated that there were statistically significant differences between the study groups regarding self-efficacy, outcome expectations and adherence to self-care behaviors in the 3 and 6-month follow-up measurement $(\mathrm{P}<0.01)$, and for the HbA1c in 6 -month follow-up measurement $(\mathrm{P}<0.05)$. There were no significant differences for the $\mathrm{HbA} 1 \mathrm{c}$ between groups in the 3-month follow-up measurement.

Repeated measures ANOVA were used to examine the differences in each variable across three-time points. The results showed that the scores obtained from diabetes self-efficacy, outcome expectations, adherence to selfcare behaviors and $\mathrm{HbA1c}$ have significantly improved in the intervention group during the study period (three and six-months after the intervention) $(\mathrm{P}<0.001)$.

Comparing subscales scores of self-care among patients before intervention showed that both control and intervention groups have the same status, while three and six-months after the intervention, the difference in mean scores of subscales of physical activity, diet and foot care in the two groups were significant $(\mathrm{P}<0.001)$. This difference in scales for self-monitoring of blood glucose and taking medications was not statistically significant $(\mathrm{P}>0.05)$ (Table 2).

\section{Discussion}

This randomized controlled trial tested the hypothesis that implementing the theory-based intervention led to improved adherence to self-care and metabolic control in patients with type- 2 diabetes. The first hypothesis was that adults with type 2 diabetes who received an educational intervention would have higher scores on selfefficacy. Our study showed a significant increase in the 
Table 1. Comparison the baseline characteristics of the study participants

\begin{tabular}{|c|c|c|c|c|c|}
\hline \multirow[t]{2}{*}{ Characteristics } & \multicolumn{2}{|c|}{ Intervention Group ( $n=40)$} & \multicolumn{2}{|c|}{ Control Group $(n=40)$} & \multirow[t]{2}{*}{$\mathbf{P}$} \\
\hline & $\mathbf{N}$ & $\%$ & $\mathbf{N}$ & $\%$ & \\
\hline Age (years), mean (SD) & \multicolumn{2}{|c|}{$54.71(7.1)$} & \multicolumn{2}{|l|}{$51.7(7.08)$} & 0.382 \\
\hline Duration of Disease (years), mean (SD) & \multicolumn{2}{|c|}{$5.63(4.0)$} & \multicolumn{2}{|l|}{$5.12(3.45)$} & 0.535 \\
\hline \multicolumn{6}{|c|}{ Sex } \\
\hline Male & 10 & 25 & 6 & 15 & \\
\hline Female & 30 & 75 & 34 & 85 & 0.535 \\
\hline \multicolumn{6}{|c|}{ Marital Status } \\
\hline Single & 4 & 10 & 2 & 5 & \\
\hline Married & 36 & 90 & 38 & 95 & 0.470 \\
\hline \multicolumn{6}{|c|}{ Education } \\
\hline Illiterate & 9 & 22.5 & 7 & 17.5 & \multirow{4}{*}{0.85} \\
\hline Primary School & 18 & 45 & 18 & 45 & \\
\hline Junior/Senior High School & 11 & 27.5 & 12 & 30 & \\
\hline College & 2 & 5 & 3 & 7.5 & \\
\hline \multicolumn{6}{|c|}{ Employment } \\
\hline Yes & 7 & 17.5 & 5 & 12.5 & \multirow{2}{*}{0.775} \\
\hline No & 33 & 82.5 & 35 & 87.5 & \\
\hline
\end{tabular}

mean self-efficacy scores of participants in intervention group over time; and in the follow-up, three and sixmonths after the intervention. These results may indicate the effectiveness of educational strategies of intervention. In a study conducted by Shi et al. educational strategies such as setting goals and domination on behavior and verbal persuasion are effective in improving the self-efficacy in patients (Shi et al. 2010). In another study carried out showed that the intervention based on self-efficacy theory was effective in improving the selfefficacy in patients (Ha et al. 2014). Results of the present study are consistent with the results of other studies and are a scientific documentary on the effectiveness of these educational strategies in increasing self-efficacy in diabetic patients.

The second hypothesis was that adults with type 2 diabetes who received an educational intervention would have higher scores on outcome expectations. Therefore, outcome expectations of patients from the implementation of self-care behaviors to improve their compliance with the mentioned behaviors were targeted. In this regard, by providing comprehensive education about psychological and physical benefits of adherence to selfcare behaviors and emphasizing positive consequences of behavior, it was tried to make a context in which the patients could achieve positive beliefs about self-care behaviors. In this respect, the results after the intervention showed a significant increase in the mean score of outcome expectations of participants in the intervention group over time, and in the follow-ups three and six months after the intervention.

A previous study has shown that using educational strategies should increase outcome expectations among the participants. Although, paying attention to the outcome expectation construct and improvement of patients' beliefs about the consequences of adherence to self-care behaviors, especially in interventions that target patients' self-efficiency improvement, can be beneficial. But few studies have considered these construct simultaneously. However, these results are consistent with $\mathrm{Wu}$ 
Table 2. Comparisons of the study variables in intervention group and control group before and after the intervention

\begin{tabular}{|c|c|c|c|c|c|}
\hline \multirow{2}{*}{ Variable } & \multirow{2}{*}{ Group } & \multirow{2}{*}{$\begin{array}{c}\text { Pre-Intervention } \\
\text { Mean (SD) }\end{array}$} & \multirow{2}{*}{$\begin{array}{c}\text { 3-Month After } \\
\text { Intervention } \\
\text { Mean (SD) }\end{array}$} & \multirow{2}{*}{$\begin{array}{c}\text { 6-Month After } \\
\text { Intervention } \\
\text { Mean (SD) }\end{array}$} & \multirow{2}{*}{ R.M. ANOVA } \\
\hline & & & & & \\
\hline \multirow{3}{*}{ Self-efficacy } & Intervention & $88.45(24.92)$ & $111.31(32.27)$ & 115.76 (32.05) & $\begin{array}{c}P<0.001 \\
F=166.13 \\
E S=0.81\end{array}$ \\
\hline & Control & $90.56(24.42)$ & $90.88(24.62)$ & $90.67(25.25)$ & $\begin{aligned} P & =0.779 \\
F & =0.04 \\
E S & =0.001\end{aligned}$ \\
\hline & $\mathrm{t}$ test & $P=0.702$ & $P=0.002$ & $P=0.001$ & \\
\hline \multirow{3}{*}{$\begin{array}{l}\text { Outcome-expec- } \\
\text { tations }\end{array}$} & Intervention & $62.8(10.8)$ & 70.25 (12.54) & 72.27 (11.66) & $\begin{array}{l}P<0.001 \\
F=67.37 \\
E S=0.63\end{array}$ \\
\hline & Control & $63.25(10.8)$ & $62.52(9.85)$ & $62.87(9.51)$ & $\begin{aligned} P & =0.698 \\
F & =0.36 \\
E S & =0.009\end{aligned}$ \\
\hline & $\mathrm{t}$ test & $P=0.853$ & $P=0.003$ & $P<0.001$ & \\
\hline \multirow{3}{*}{ Self-care } & Intervention & 39.87 (9.7) & 48.95 (11.58) & $51.65(11.53)$ & $\begin{array}{l}P<0.001 \\
F=99.14 \\
E S=0.71\end{array}$ \\
\hline & Control & $40.26(9.41)$ & 40.94 (9.12) & $40.23(9.16)$ & $\begin{aligned} P & =0.228 \\
F & =1.5 \\
E S & =0.03\end{aligned}$ \\
\hline & $\mathrm{t}$ test & $P=0.859$ & $P=0.001$ & $P<0.001$ & \\
\hline \multirow{3}{*}{$\mathrm{HbA1c}$} & Intervention & $8.4(1.06)$ & $8.17(1.12)$ & $8.07(1.16)$ & $\begin{array}{c}P<0.001 \\
F=9.91 \\
E S=0.2\end{array}$ \\
\hline & Control & $8.46(1.08)$ & $8.43(1.06)$ & 8.49 (1.03) & $\begin{array}{c}P=0.674 \\
F=0.39 \\
E S=0.01\end{array}$ \\
\hline & $t$ test & $P=0.094$ & $P=0.296$ & $P<0.05$ & \\
\hline
\end{tabular}

et al. study pointing out that educational interventions have been effective in improving outcome expectations for better adherence to self-care behaviors (Wu 2007).

The other hypothesis was that type 2 diabetic adults who got an educational intervention would have better self-care behaviors. In this regard, the results showed that after the intervention, a significant increase has been created in the mean score of participants' self-care in the intervention group over time, compared with the control group. These results may indicate the effectiveness of intervention and strategies employed to influence self-efficacy and outcome expectations that finally led to better self-care in diabetics. These results are consistent with a previous study carried out by Pena-Purcell et al. (Peña-Purcell, Boggess \& Jimenez 2011). The other study done by Anderson et al. also showed that educational intervention acted effectively in empowering patients and increasing their self-efficacy so that after 12 weeks, improvements in self-care and blood glucose were observed in them (Anderson et al. 1995).
The other results indicated that three and six-months after the intervention, the difference in mean scores of self-care subscales of physical activity, diet and foot care in the two groups were significant. This difference in subscales for self-monitoring of blood glucose and taking medications were not statistically significant. In some studies, financial constraints and high cost were reported as the most important reason for the failure to do self-monitoring of blood glucose, and unfortunately, we could not do something for it (Karter et al. 2000). Since based on studies, self-care behaviors play an important role in achieving normal glucose range, and certainly, it can be considered as an integral part of effective management of diabetes (Sorani et al. 2012).

In the present study, all the educational interventions and strategies were designed in order to enhance the adherence to self-care behaviors that can lead to the reduction in blood sugar levels. Therefore, the other hypothesis was that adults with type 2 diabetes who received an educational intervention would have a reduction in blood sugar levels, and HbAlc levels was evaluated in patients 


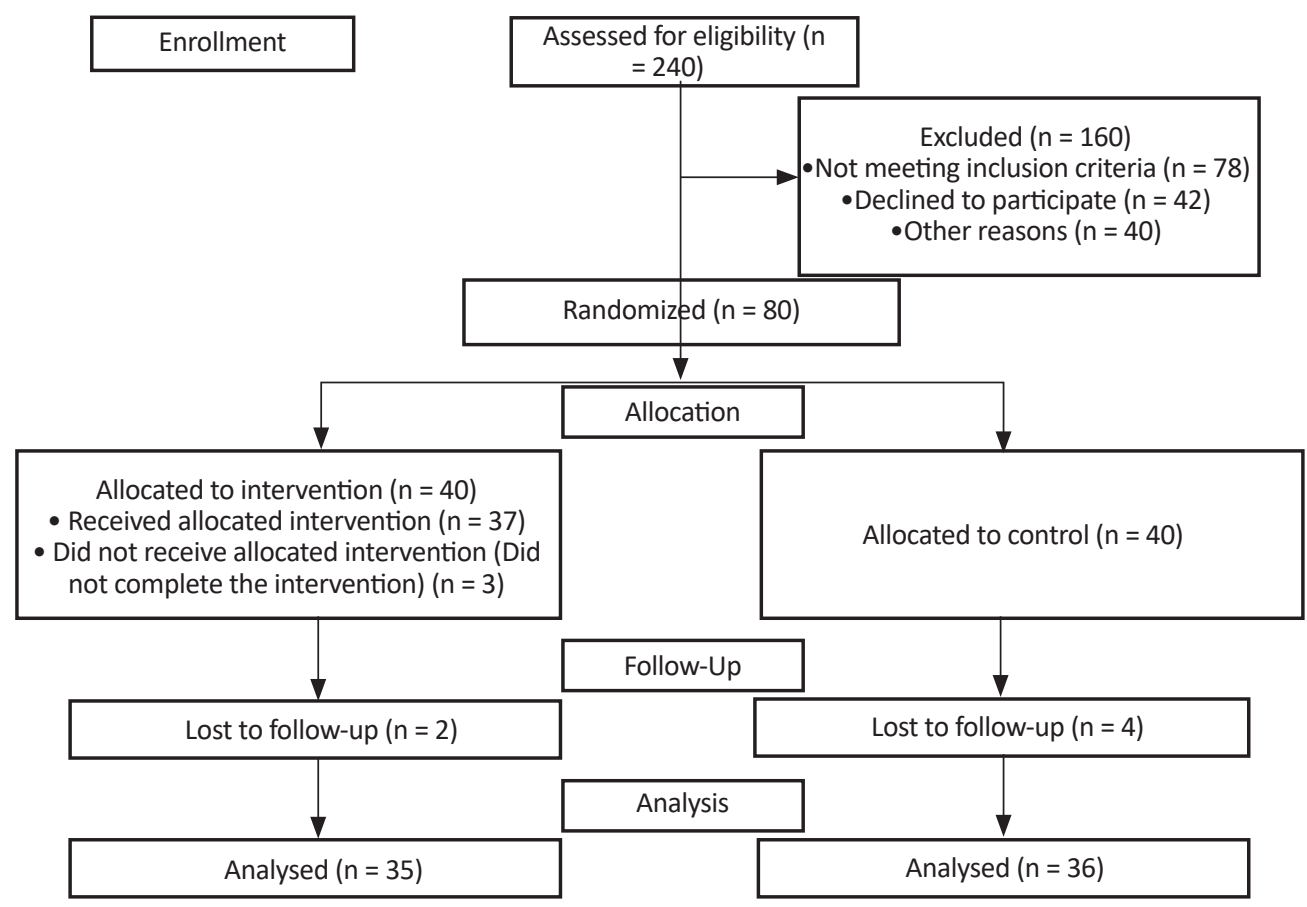

Figure 1. Consort flow of the study participants

Client-Centered Nursing Care

as the main behavioral outcome. The results after the intervention showed a significant decrease in levels of $\mathrm{HbA} 1 \mathrm{c}$ of patients in the intervention group compared with the control group, both during and six-month after the intervention, which is the same as previous studies (Zareban et al. 2013; Tuomilehto et al. 2001).

Although the HbAlc of the intervention group had a decreasing trend in follow-ups, but there was no significant difference between two groups of the study in 3-months for this variable. Considering the improvement of selfcare behaviors of the subjects as they reported in the first follow up, it was expected to see a significant difference in the HbA1c scores of them too. Since then the instrument was used to assess the self-care behavior based on self-reporting for only the last seven days of the subject's behavior, so this result could be the indication of a short period of time before the follow-up and may not have

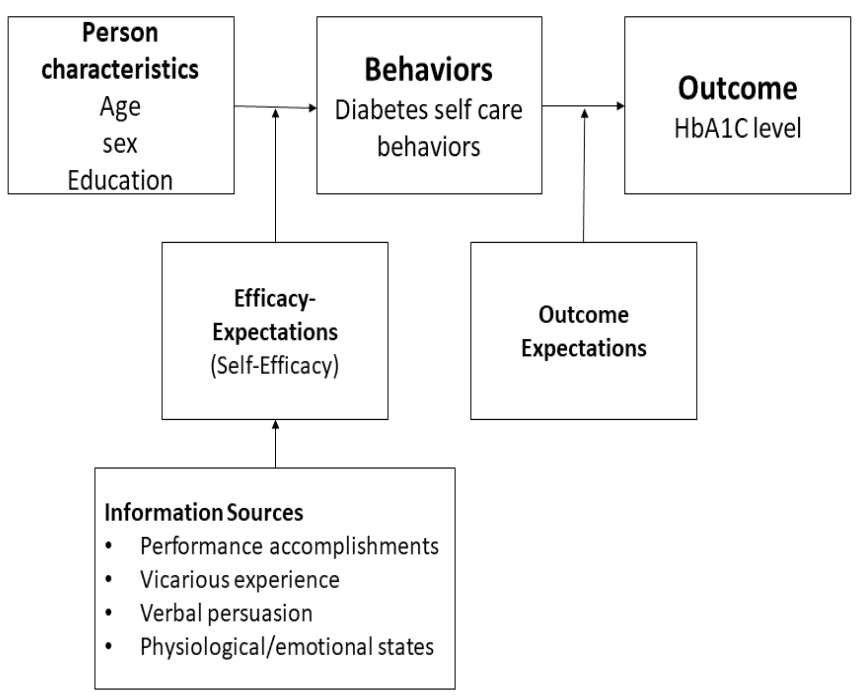

Client-Centered Nursing Care

Figure 2. Conceptual framework (Self-efficacy model adapted from Shortridge-Baggett and Van der Bijl (1996)

A theory-based educational intervention was applied to individuals with diabetes to increase self-efficacy and outcome expectations in order to impact health care behaviors and glycemic control. 
the power to represent the long-term behavior that could have an effect on the HbAlc test scores.

In general, these results supported previous researchers who observed the effects of educational intervention on self-care and reduction of the level of $\mathrm{HbA} 1 \mathrm{c}$ in diabetic patients (Miller et al. 2002). In this regard, a study showed that using proper strategies like succession experiences and verbal persuasion, some methods like setting goals and role playing have been effective in improving diabetes self-care, followed by a reduction in blood sugar (Ha et al. 2014). Eventually, the findings of this study show the effect of theory-based intervention on self-care and ultimately reduction of patients' blood sugar. Indeed, this educational intervention focuses on behavioral change, and it was different from the usual diabetes education which focuses only on the transformation of information or skills. Therefore, the use of these strategies is recommended in patient education in the field of metabolic control. Also, in the further research, the study of the effectiveness of other behavioral change theories on self-care behavior and blood glucose control in diabetic patients is recommended.

This study had several limitations. Older age and depression that is usually seen in the majority of patients with diabetes as an accompanying disease is considered as one of the most important limitations of this study and sometimes prevented the complete implementation of the intervention. As we have used convenience sampling method and small sample size, the results may not be generalized to the broader population of adults with type 2 diabetes. Also, since there was no possibility of blinding the participants in this study, bias or exaggeration in response to the questions was possible.

\section{Acknowledgements}

This research did not receive any specific grant from funding agencies in the public, commercial, or not-forprofit sectors.

\section{Conflict of Interest}

The authors declared no conflicts of interest.

\section{References}

Aljasem, L. I. et al., 2001. The impact of barriers and self-efficacy on self-care behaviors in type 2 diabetes. The Diabetes Educator, 27(3), pp. 393-404. [DOI:10.1177/014572170102700309]

Anderson, R. M. et al., 1995. Patient empowerment: Results of a randomized controlled trial. Diabetes Care, 18(7), pp. 943-9. [DOI:10.2337/diacare.18.7.943]

Bandura, A., 1986. Social foundations of thought and action: A social cognitive theory. Englewood Cliffs, NJ: Prentice-Hall, Inc.

Bandura, A., 1997. Self-efficacy: The exercise of control. New York: Freeman.

Bashirian, S., et al., 2012. [Application of theory of planned behavior in predicting factors of substance abuse in adolescents (Persian)]. Journal of Fasa University of Medical Sciences, 2(3), pp. 156-62.

Bijl, J. van der, Poelgeest-Eeltink, A. van \& Shortridge-Baggett, L., 1999. The psychometric properties of the diabetes management self-efficacy scale for patients with type 2 diabetes mellitus. Journal of Advanced Nursing, 30(2), pp. 352-9. [DOI:10.1046/j.1365-2648.1999.01077.x]

Brettenthaler, N. et al., 2004. Effect of the insulin sensitizer pioglitazone on insulin resistance, hyperandrogenism, and ovulatory dysfunction in women with polycystic ovary syndrome. The Journal of Clinical Endocrinology $\mathcal{E}$ Metabolism, 89(8), pp. 3835-40. [DOI:10.1210/jc.2003-031737]

Didarloo, A. R., et al., 2012. Prediction of self-management behavior among Iranian women with type 2 diabetes: Application of the theory of reasoned action along with self-efficacy (etra). Iranian Red Crescent Medical Journal, 14(2), p. 86. [PMID] [PMCID]

Eckman, M. H. et al., 2012. Impact of health literacy on outcomes and effectiveness of an educational intervention in patients with chronic diseases. Patient Education and Counseling, 87(2), pp. 143-51. [DOI:10.1016/j.pec.2011.07.020]

Franz, M. J., et al., 2004. Nutrition principles and recommendations in diabetes. Diabetes Care, 27, pp. S36-46. [DOI:10.2337/ diacare.27.2007.S36] [PMID]

Funnell, M. M., 2006. The diabetes attitudes, wishes, and needs (DAWN) study. Clinical Diabetes, 24(4), pp. 154-5. [DOI:10.2337/diaclin.24.4.154]

Ha, M. et al., 2014. The effects of an educational self-efficacy intervention on osteoporosis prevention and diabetes self-management among adults with type 2 diabetes mellitus. Biological Research For Nursing, 16(4), pp. 357-67. [DOI:10.1177/1099800413512019]

Haghayegh, A. S., Ghasemi, N., Neshatdoost, H.T., Kajbaf, M and Khanbani, M., 2010. Psychometric properties of Diabetes Management Self-Efficacy Scale (DMSES). Iranian Journal of Endocrinology and Metabolism, 12(2), pp. 111-95.

International Diabetes Federation. Diabetes Atlas 2013. Brussels: International Diabetes Federation.

Karter, A. J. et al., 2000. Self-monitoring of blood glucose: language and financial barriers in a managed care population with diabetes. Diabetes Care, 23(4), pp. 477-83. [DOI:10.2337/ diacare.23.4.477] 
King, D. K. et al., 2010. Self-efficacy, problem solving, and social-environmental support are associated with diabetes self-management behaviors. Diabetes Care, 33(4), pp. 751-3. [DOI:10.2337/dc09-1746]

Lendemeijer, B. \& Shortridge-Baggett, L., 1997. The use of seclusion in psychiatry: A literature review. Scholarly Inquiry for Nursing Practice, 11(4), pp. 299-315. [PMID]

Miller, C. K. \& Gutschall, M., 2008. A randomized trial about glycemic index and glycemic load improves outcomes among adults with type 2 diabetes. Health Education \& Behavior, 36(3), pp. 615-26. [DOI:10.1177/1090198108317598]

Miller, C. K. et al., 2002. Evaluation of a theory-based nutrition intervention for older adults with diabetes mellitus. Journal of the American Dietetic Association, 102(8), pp. 1069-81. [DOI:10.1016/S0002-8223(02)90242-7]

Moattari, M. et al., 2012. Impact of self management on metabolic control indicators of diabetes patients. Journal of Diabetes $\mathcal{E}$ Metabolic Disorders, 11(1), p. 6. [DOI:10.1186/2251-6581-11-6]

Morrish, N. J. et al., 2001. Mortality and causes of death in the WHO multinational study of vascular disease in diabetes. Diabetologia, 44(S2), pp. S14-S21. [DOI:10.1097/01. NAJ.0000277829.28043.93]

Nath, C., 2007. Literacy and diabetes self-management. American Journal of Nursing, 107(Supplement), pp. 43-9. [DOI:10.1097/01.NAJ.0000277829.28043.93]

Peña-Purcell, N. C., Boggess, M. M. \& Jimenez, N., 2011. An empowerment-based diabetes self-management education program for Hispanic/Latinos. The Diabetes Educator, 37(6), pp. 770-9. [DOI:10.1177/0145721711423319]

Piccinino, L. et al., 2015. Recent trends in diabetes knowledge, perceptions, and behaviors. Health Education $\mathcal{E}$ Behavior, 42(5) pp. 687-96. [DOI:10.1177/1090198115577373]

Reisi, M. et al., 2016. Impact of health literacy, self-efficacy, and outcome expectations on adherence to self-care behaviors in Iranians with type 2 diabetes. Oman Medical Journal, 31(1), pp. 52-9. [DOI:10.5001/omj.2016.10]

Reisi, M. et al., 2015. Assessment of some predicting factors of self-efficacy in patients with type 2 diabetes. Iranian Journal of Endocrinology and Metabolism, 17(1), pp. 44-52.

Roglic, G. et al., 2005. The burden of mortality attributable to diabetes: Realistic estimates for the year 2000. Diabetes Care, 28(9), pp. 2130-5. [DOI:10.2337/diacare.28.9.2130]

Sherer, M. et al., 1982. The self-efficacy scale: Construction and validation. Psychological Reports, 51(2), pp. 663-71. [DOI:10.2466/pr0.1982.51.2.663]

Shi, Q., Ostwald, S. K. \& Wang, S., 2010. Improving glycaemic control self-efficacy and glycaemic control behaviour in Chinese patients with Type 2 diabetes mellitus: randomised controlled trial. Journal of Clinical Nursing, 19(3-4), pp. 398-404 [DOI:10.1111/j.1365-2702.2009.03040.x]

Sicree, R., Shaw, J., \& Zimmet, P. , 2010. The global burden of diabetes: Diabetes and impaired glucose tolerance. Prevalence and Projections. IDF Atlas, pp. 10-104.

Sigurðardóttir, Á. K., 2005. Self-care in diabetes: model of factors affecting self-care. Journal of Clinical Nursing, 14(3), pp. 301-14. [DOI:10.1111/j.1365-2702.2004.01043.x]
Skelly, A. H. et al., 1995. Self-efficacy and confidence in outcomes as determinants of self-care practices in inner-city, African-American women with non-insulin-dependent diabetes. The Diabetes Educator, 21(1), pp. 38-46. [DOI:10.1177/0145721 79502100107]

Sorani, M. et al., 2012. Predictors of self-care behaviors of patients with type 2 diabetes. Health System Research, 8, pp. 81424.

Shortridge-Baggett, L. M. \& van der Bijl, J. 1996. International collaborative research on management self-efficacy in diabetes mellitus. The Journal of the New York State Nurses Association, 27, 9-14. [PMID]

Tan, M. Y. \& Magarey, J., 2008. Self-care practices of Malaysian adults with diabetes and sub-optimal glycaemic control. Patient Education and Counseling, 72(2), pp. 252-67. [DOI:10.1016/j.pec.2008.03.017]

Toobert, D. J., Hampson, S. E. \& Glasgow, R. E., 2000. The summary of diabetes self-care activities measure: Results from 7 studies and a revised scale. Diabetes Care, 23(7), pp. 943-50. [DOI:10.2337/diacare.23.7.943]

Tuomilehto, J. et al., 2001. Prevention of type 2 diabetes mellitus by changes in lifestyle among subjects with impaired glucose tolerance. New England Journal of Medicine, 344(18), pp. 1343 50. [DOI:10.1056/NEJM200105033441801]

Van Der Bijl, J. J., \& Shortridge-Baggett, L. M., 2001. The theory and measurement of the self-efficacy construct. Scholarly Inquiry for Nursing Practice, 15, pp. 189-207. [PMID]

Wild, S. et al., 2004. Global prevalence of diabetes: Estimates for the year 2000 and projections for 2030. Diabetes Care, 27(5), pp. 1047-53. [DOI:10.2337/diacare.27.5.1047]

World Medical Association., 2001. World medical association declaration of Helsinki, ethical principles for medical research involving human subjects. Bulletin of the World Health Organization, 79(4). PMC: 2566407

Wu, S. F., 2007. Effectiveness of self-management for persons with type 2 diabetes following the implementation of a self-efficacy enhancing intervention program in Taiwan ( $\mathrm{PhD}$ dissertation). Brisbane, Queensland: Queensland University of Technology.

Yang, W. et al., 2010. Prevalence of diabetes among men and women in China. New England Journal of Medicine, 362(12), pp. 1090-101. [DOI:10.1056/NEJMoa0908292]

Zareban, I. et al., 2013. The effect of education program based on health belief model on decreasing blood sugar levels in diabetic type 2 patients in Zahedan. Health Scope, 2(2), pp. 73-8. [DOI:10.17795/jhealthscope-8690]

Zhou, Y. et al., 2013. Self-care practices of Chinese individuals with diabetes. Experimental and Therapeutic Medicine, 5(4), pp. 1137-42. [DOI:10.3892/etm.2013.945] 